\title{
Preparation of Silica Glass Fibers from Tetraethylorthosilicate and Hexamethyldisiloxane
}

\author{
Hidero UNUMA, Yoshikazu SUZUKI and Sumio SAKKA* \\ ( Government Industrial Development Laboratory, Hokkaido, 2-17, Tsukisamu-Higashi, Toyohira-ku, Sapporo-shi \\ *Institute for Chemical Research, Kyoto University, Gokasho, Uji-shi 611
}

\section{オルソケイ酸エチルとへキサメチルジシロキサンからのシリカガラス綫維の調製}

\author{
鵜沼英郎・鈴木良和・作花済夫* \\ ( 北海道工業開発試験所, 004 札幌市豊平区月寒東 2-17 $)$ \\ *京都大学化学研究所, 611 宇治市五ケ庄
}

Silica glass fibers were prepared from mixed solutions of tetraethylorthosilicate (TEOS) and hexamethyldisiloxane (HMDS). An addition of HMDS improves spinnability since the increase in the viscosity of spinnable solutions becomes moderate and the range of the amount of added water for the occurrence of spinnability is widened. Spinnable solutions are obtained when the ratio of silicon in HMDS to total silicon, $r$, ranges from 0 to 0.6 . It is assumed that the fibers drawn from this system consist of linear polymeric particles with double or triple siloxane chains capped with trimethylsilyl groups. Gel fibers from the solutions of $r \leqq 0.5$ were converted to visually colorless and transparent silica glass fibers by rapidly heating them at $600^{\circ} \mathrm{C}$.

[Received October 20, 1988; Accepted December 15, 1988]

Key-words : Sol-gel method, Fiber, Silica glass, Silica gel, Tetraethylorthosilicate, Hexamethyldisiloxane, Spinnability

\section{Introduction}

Sakka and co-workers ${ }^{1-5)}$ prepared silica gel fibers through hydrolysis and polymerization of tetraethyl-orthosilicate (TEOS) and converted them to silica glass fibers by heating them up to a temperature range from $500^{\circ}$ to $800^{\circ} \mathrm{C}$. Silica gel fibers were obtained from the solutions posessing viscosities larger than about ten poise. Ohta ${ }^{6}$ developed Sakka's method and found that the silica glass fibers prepared from TEOS have better properties than those obtained by fusion of quartz. Kamiya et al. ${ }^{7)}$ prepared $\mathrm{Si}-\mathrm{O}-\mathrm{N}$ oxynitride glass fibers from methyltriethoxysilane. Physics and chemistry of the fiber-drawing from metal alkoxides have been studied by Sakka and co-workers ${ }^{8)-10)}$ and Brinker and Scherer. ${ }^{11}$ Other methods have also been studied; instead of silicate ester, Abe et al. ${ }^{12)}$ used silicic acid derived from sodium metasilicate and Yanaginuma et al. ${ }^{13 \prime}$ used water glass.

These methods, however, have difficulties that the viscosity of spinnable solutions rapidly increases during fiber-drawing. Uptaking of moisture in air has to be minimized. LeCourse et al. ${ }^{14)}$ elongated the duration for fiber-drawing by diluting spinnable solutions with ethyl alchol, and Ohta ${ }^{6}$ cooled spinnable solutions below room temperature.

In this paper, we report the preparation of silica glass fibers from mixed solutions of TEOS and hexamethyldisiloxane (HMDS). The composition range exhibiting spinnability has been determined. Spinnability has been improved by the addition of HMDS; the increase in the viscosity of spinnable solutions becomes moderate and the range of the amount of water which can be used without losing spinnability of the solution is widened. Conversion of gel fibers to silica glass fibers has been attempted. The structure of the fibers obtained in this method is discussed.

\section{Experimental}

\subsection{Preparation of solutions and gel fibers}

Table 1 shows the compositions of the solutions used in this study. The total amount of silicon in each batch was adjusted at $0.1 \mathrm{~mol}$, considering that one mole of HMDS contains two moles of silicon. The ratio of silicon in HMDS to total silicon, $r$, was varied from 0 to 0.667 . The ratio of the added water to the total silicon was varied from 0.7 to 15. TEOS (Kishida Kagaku) and HMDS (Shin-etsu Kagaku Kogyo) were diluted with $99.5 \mathrm{vol} \%$ ethanol in $100 \mathrm{ml}$ beakers. Distilled water and nitric acid diluted with ethanol were dropwisely added to the former solutions under vigorous stirring. The amount of nitric acid added to each solution was $0.001 \mathrm{~mol}$. The amount of ethanol, which does not affect fiberdrawing behavior, was controlled to avoid immiscibility of the solutions. The solutions were kept 
Table 1. Compositions and spinnabilities of TEOS-HMDS- $\mathrm{H}_{2} \mathrm{O}-\mathrm{HNO}_{3}-$ $\mathrm{C}_{2} \mathrm{H}_{5} \mathrm{OH}$ solutions.

\begin{tabular}{|c|c|c|c|c|c|c|c|c|}
\hline No. & $\begin{array}{l}\text { TEOS } \\
(\mathrm{mol})\end{array}$ & $\begin{array}{l}\text { HMDS } \\
\text { (mol) }\end{array}$ & $r$ & $\begin{array}{c}\mathrm{H} 2 \mathrm{O}^{*} \\
(\mathrm{~mol})\end{array}$ & $\mathrm{C}_{2} \mathrm{H}_{5} \mathrm{OH}$ & $\begin{array}{l}\text { Spinn- } \\
\text { ability }\end{array}$ & $\begin{array}{l}\text { Duration for } \\
\text { drawing }(\mathrm{h})\end{array}$ & $\begin{array}{l}\text { Max. length } \\
\text { of a fiber }(\mathrm{cm})\end{array}$ \\
\hline $0-1$ & \multirow{5}{*}{0.1} & \multirow{5}{*}{0} & \multirow{5}{*}{0} & 0.1 & 12 & no ${ }^{\text {a) }}$ & - & - \\
\hline $0-1.2$ & & & & 0.12 & 12 & $n^{\text {a ) }}$ & - & - \\
\hline $0-1.5$ & & & & 0.15 & 12 & yes & 0.3 & 20 \\
\hline $0-2$ & & & & 0.2 & 12 & yes & 0.2 & 10 \\
\hline $0-4$ & & & & 0.4 & 12 & no & - & - \\
\hline $25-0.7$ & \multirow{7}{*}{0.075} & \multirow{7}{*}{0.0125} & \multirow{7}{*}{0.25} & 0.07 & 12 & $n^{a)}$ & - & - \\
\hline $25-1$ & & & & 0.1 & 21 & yes & 3 & 60 \\
\hline $25-1.2$ & & & & 0.12 & 15 & yes & 2 & 50 \\
\hline $25-1.5$ & & & & 0.15 & 21 & yes & 2.5 & 60 \\
\hline $25-3$ & & & & 0.3 & 21 & yes & 2 & 50 \\
\hline $25-6$ & & & & 0.6 & 26 & yes & 1.5 & 30 \\
\hline $25-10$ & & & & 1.0 & 44 & no & - & - \\
\hline $30-0.7$ & \multirow{2}{*}{0.07} & \multirow{2}{*}{0.015} & \multirow{2}{*}{0.3} & 0.07 & 12 & $\mathrm{no}^{\mathrm{a})}$ & - & - \\
\hline $30-1$ & & & & 0.1 & 15 & yes & 1.5 & 40 \\
\hline $40-1$ & \multirow{2}{*}{0.06} & \multirow{2}{*}{0.02} & \multirow{2}{*}{0.4} & 0.1 & 15 & no ${ }^{a)}$ & - & - \\
\hline $40-2$ & & & & 0.2 & $2 I$ & yes & 2.5 & 60 \\
\hline $50-2$ & \multirow{6}{*}{0.05} & \multirow{6}{*}{0.025} & \multirow{6}{*}{0.5} & 0.2 & 22 & $\mathrm{no}^{\text {a) }}$ & - & - \\
\hline $50-3$ & & & & 0.3 & 21 & yes & 2 & 70 \\
\hline $50-4$ & & & & 0.4 & 21 & yes & 2.5 & 60 \\
\hline $50-6$ & & & & 0.6 & 31 & yes & 3.5 & 60 \\
\hline $50-10$ & & & & 1.0 & 36 & yes & 2 & 40 \\
\hline $50-15$ & & & & 1.5 & 53 & no & - & - \\
\hline $60-2$ & \multirow{4}{*}{0.04} & \multirow{4}{*}{0.03} & \multirow{4}{*}{0.6} & 0.2 & 22 & $n^{a)}$ & - & - \\
\hline $60-5$ & & & & 0.5 & 26 & yes & 4 & 150 \\
\hline $60-8$ & & & & 0.8 & 46 & yes & 1.5 & 70 \\
\hline $60-15$ & & & & 1.5 & 54 & no & - & - \\
\hline $66.7-3$ & \multirow{3}{*}{0.0333} & \multirow{3}{*}{0.0667} & \multirow{3}{*}{0.667} & 0.3 & 21 & $\mathrm{no}^{\mathrm{a})}$ & - & - \\
\hline $66.7-6$ & & & & 0.6 & 40 & no & - & - \\
\hline $66.7-10$ & & & & 1.0 & 53 & no ${ }^{a)}$ & - & - \\
\hline MTES-2 & $0.1^{\text {C) }}$ & - & - & 0.2 & 21 & yes & 0.3 & 20 \\
\hline
\end{tabular}

Added water contains $0.001 \mathrm{~mol}$ of HNO3.

The solution does not solidify (not-gelling).

The solution solidifies without exhibiting spinnability (not-spinnable).

c) Amount of methyltriethoxysilane.

stirred at room temperature for 1 hour in the beakers tightly covered with polyvinylidenechloride films, in order to avoid evaporation of the constituents. Then, the covers were removed and the solutions were kept in an oven to promote reactions. The temperature and the relative humidity in the oven were kept at $50^{\circ} \mathrm{C}$ and $20 \%$, respectively. When the solvents evaporated too fast, the solutions became immiscible, especially in the solutions containing a large amount of HMDS. Hence, the evaporation rate of the solvents was controlled by covering the beakers with aluminum foils with holes. When the solution became viscous, the spinnability was tested by dipping a polypropylene rod into the solutions and pulling it up manually. Fibers were drawn at room temperature.

\subsection{Heat-treatment of gel fibers}

Gel fibers were heat-treated in an electric furnace at $600^{\circ}, 700^{\circ}$ and $800^{\circ} \mathrm{C}$ for 1 hour.

\section{Results}

\subsection{Relation between spinnability and com- position}

Figure 1 shows a relation between spinnability and composition. HMDS is represented as $\left(\mathrm{CH}_{3}\right)_{3} \mathrm{SiO}_{1 / 2}$. Filled circles indicate spinnable

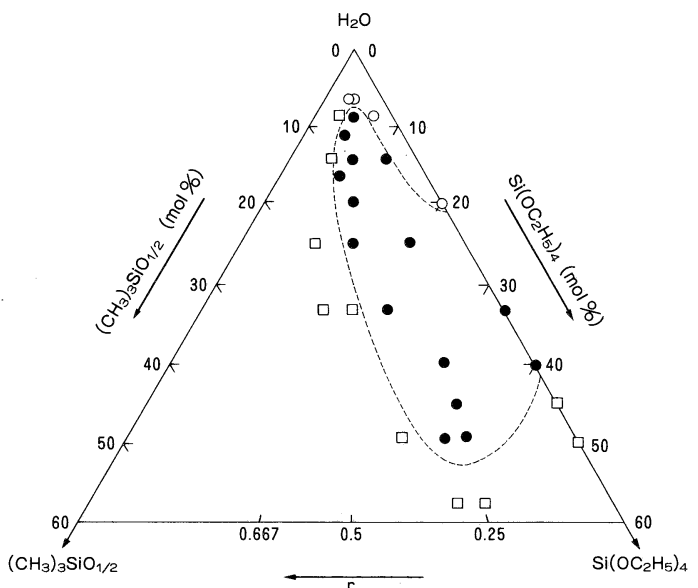

Fig. 1. Relation between spinnability and composition of TEOS-HMDS- $\mathrm{H}_{2} \mathrm{O}-\mathrm{HNO}_{3}-\mathrm{C}_{2} \mathrm{H}_{5} \mathrm{OH}$ solutions with $\left[\mathrm{HNO}_{3}\right] /[$ total Si $]=0.01$ hydrolyzed at $50^{\circ} \mathrm{C}$ and $20 \%$ relative humidity;

(O) spinnable, $(\square)$ not-gelling $(\bigcirc)$ and notspinnable. HMDS is represented as $\left(\mathrm{CH}_{3}\right)_{3} \mathrm{SiO}_{1 / 2}$. The amount of $\mathrm{C}_{2} \mathrm{H}_{5} \mathrm{OH}$ is not shown since it does not affect spinnability.

compositions. For compositions containing too large an amount of water, represented by open circles, solutions solidified without exhibiting 
spinnability (not-spinnable). For compositions with insufficient water, indicated by open squares, fibers were not obtained because the solutions did not solidify in a reasonable time period (not-gelling). The duration for possible drawing and the maximum length of a drawn fiber is shown in Table 1. The range of the amount of water for the solutions exhibiting spinnability is widened with an increase in $r$. The minimum amount of water necessary for the occurrence of spinnability (MIW) is at first reduced as $r$ increases from 0 to 0.25 , then MIW increases with an increase in $r$ from 0.25 to 0.6 . The maximun amount of water permissible for the occurrence of spinnability (MAW) increases monotonously with an increase in $r$. The limiting value of $r$ for the occurrence of spinnability ranges between 0.6 and 0.667 . The duration for drawing is elongated and the spinnability, as expressed by the maximum length of a drawn fiber, is improved with an increase in $r$ since the increase in the viscosity of spinnable solutions becomes moderate. When $r$ ranges from 0.25 to 0.6 , the almost all the starting solution is drawn into fibers. In contrast, only a small amount of fibers can be drawn when $r=0$. For comparison, the result for methyltriethoxysilane (MTES) is shown. MTES shows a fiber-drawing behavior similar to TEOS.

\subsection{Heat-treatment of gel fibers}

Gel fibers obtained from the solutions of $r \leqq 0.5$ were converted to silica glass fibers by the heat-treatments. When they were heated rapidly up to $600^{\circ} \mathrm{C}$, transparent and colorless glass fibers were produced. Heating gel fibers rapidly up to $700^{\circ}$ or $800^{\circ} \mathrm{C}$ resulted in coloration of the fibers in black. Once the gel fibers were heated at $600^{\circ} \mathrm{C}$, coloration did not occur after re-heating them rapidly up to $800^{\circ} \mathrm{C}$. Gel fibers from the solutions of $r=0.6$ could not be con-

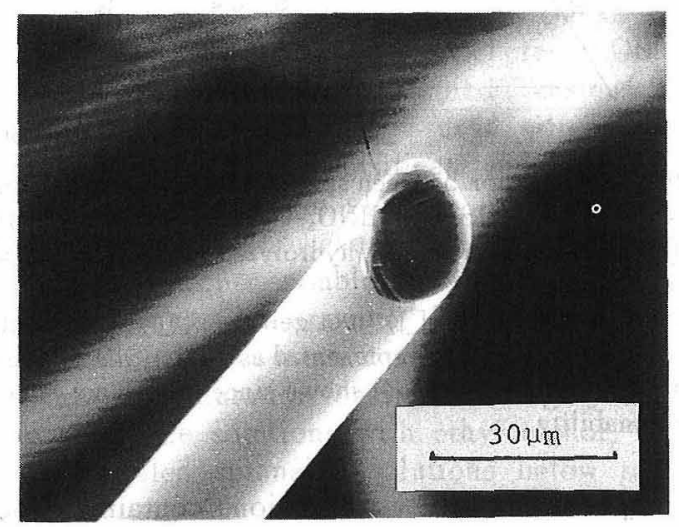

Fig. 2. A picture of silica glass fibers prepared from No. 50-10 solution; heat-treated at $700^{\circ} \mathrm{C}$ for 1 hour. verted to silica glass fibers since they melted and turned into a porous silica monolith.

A picture of glass fibers of No. 50-10 heated at $700^{\circ} \mathrm{C}$ for 1 hour is shown in Fig. 2. Silica glass fibers of 5 to $30 \mu \mathrm{m}$ in diameter were obtained. The shape of cross section of the fibers obtained by using HMDS is almost circular.

\section{Discussion}

HMDS undergoes hydrolysis by the reaction : $\left(\mathrm{CH}_{3}\right)_{3} \mathrm{Si}-\mathrm{O}-\mathrm{Si}\left(\mathrm{CH}_{3}\right)_{3}+\mathrm{H}_{2} \mathrm{O} \rightleftarrows$

$$
2\left(\mathrm{CH}_{3}\right)_{3} \mathrm{SiOH}
$$

TEOS undergoes hydrolysis and polymerization by the reactions :

$$
\begin{aligned}
& \left(\mathrm{C}_{2} \mathrm{H}_{5} \mathrm{O}\right)_{4} \mathrm{Si}+n \mathrm{H}_{2} \mathrm{O} \rightarrow \\
& \quad\left(\mathrm{C}_{2} \mathrm{H}_{5} \mathrm{O}\right)_{4-n} \mathrm{Si}(\mathrm{OH})_{n}+n \mathrm{C}_{2} \mathrm{H}_{5} \mathrm{OH} \\
& 2\left(\mathrm{C}_{2} \mathrm{H}_{5} \mathrm{O}\right)_{4-n} \mathrm{Si}(\mathrm{OH})_{n} \rightarrow \\
& \left(\mathrm{C}_{2} \mathrm{H}_{5} \mathrm{O}\right)_{4-n} \mathrm{Si}-\mathrm{O}-\mathrm{Si}\left(\mathrm{OC}_{2} \mathrm{H}_{5}\right)_{4-n}+\mathrm{H}_{2} \mathrm{O}
\end{aligned}
$$

When the ratio of the amount of water to TEOS is limited to $1.5-4$, spinnability occurs since linear polymeric particles are produced. ${ }^{1,, 5,8), 9,11)}$

Trimethylsilanol, the product of the hydrolysis of HMDS, reacts with $\mathrm{Si}-\mathrm{OH}$ or $\mathrm{Si}-\mathrm{OC}_{2} \mathrm{H}_{5}$ group and stops further polymerization, ${ }^{5), 15)}$ which is referred to as trimethylsilylation (TMS);

$$
\begin{gathered}
\left(\mathrm{CH}_{3}\right)_{3} \mathrm{Si}-\mathrm{OH}+\mathrm{RO}-\mathrm{Si} \equiv \rightarrow \\
\left(\mathrm{CH}_{3}\right)_{3} \mathrm{Si}-\mathrm{O}-\mathrm{Si} \equiv+\mathrm{ROH} \\
\left(\mathrm{R}=\mathrm{C}_{2} \mathrm{H}_{5} \text { or } \mathrm{H}\right)
\end{gathered}
$$

In strongly acidic conditions with a large excess of HMDS, TMS is quantitative and the polymerization of TEOS is virtually suppressed. ${ }^{16)}$ However, in weakly acidic conditions as in the present case, reactions (1) to (4) would proceed simultaneously. As reaction (4) proceeds, equiliblium (1) would shift to right hand side and the hydrolysis of HMDS would be completed. As a result, partly TMS'ed orthosilicate units

$$
\left(\left(\mathrm{CH}_{3}\right)_{3} \mathrm{Si}-\mathrm{O}-\right)_{n} \mathrm{Si}(\mathrm{OR})_{4-n} \quad(n \leqq 3)
$$

would occur and such species would construct polymeric particles.

The type of partly TMS'ed units would be dependent on the value of $r$. Statistically, when $r$ is smaller than 0.5 , major constituents would be non-TMS'ed orthosilicate units and singly TMS'ed orthosilicate units (6).

$$
\left(\mathrm{CH}_{3}\right)_{3} \mathrm{Si}-\mathrm{O}-\mathrm{Si} \equiv
$$

When $r$ is 0.5 , ( 6 ) would be the major one. When $r$ exceeds 0.5 , doubly TMS'ed orthosilicate units

$$
\left(\left(\mathrm{CH}_{3}\right)_{3} \mathrm{Si}-\mathrm{O}\right)_{2}=\mathrm{Si}=
$$

would increase with an increase in $r$ and when $r$ is $0.667,(7)$ would be the major one. If $r$ is bigger than $0.667,(7)$ and triply TMS'ed orthosilicate units, which obviously does not 
form linear polymers, would be the main species.

In case of fiber-drawing from TEOS and MTES, linear polymeric particles with triple and double siloxane chains would be produced, ${ }^{8), 17)}$ respectively. Sakka et al. ${ }^{8)}$ studied the spinnability of the solutions prepared from MTES and dimethyldiethoxysilane (DMDES), and found that the solutions prepared from the former exhibit spinnability while those prepared from the latter do not. They concluded that the oligomers with only single siloxane chain resulted from DMDES,

$$
\left(-\mathrm{Si}\left(\mathrm{CH}_{3}\right)_{2}-\mathrm{O}-\right)_{n}
$$

are so flexible that they can not remain linear polymeric particles responcible for spinnability.

(6) and ( 7 ) may correspond to MTES and DMDES since they have three and two functional groups, respectively. The present experimental result, that spinnability occurs when $r$ is less than 0.667 , is analogous to the result of Sakka et al. ${ }^{8)}$

Considering the limiting value of $r$ for the occurrence of spinnability, 0.667 , it is assumed that the structure of the fibers obtained from the present system would also be linear polymeric particles containing double and triple siloxane chains capped with trimethylsilyl groups, depending on the value of $r$.

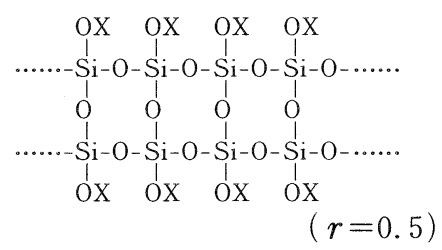

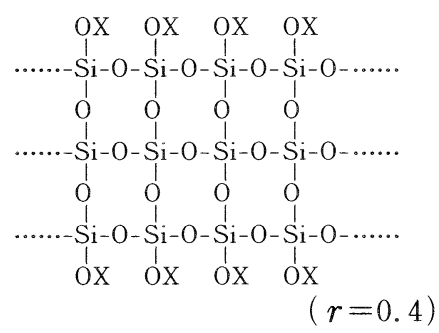

where $\mathrm{X}$ represents a trimethylsilyl group. When $r$ is bigger than $0.5,(7)$ would terminate chains (8) and make the chains shorter. It would weaken the structure of the fibers. The experimental result that the fibers obtained from the solutions of $r=0.6$ could not be converted to glass fibers, would support this consideration.

The increase in the viscosity of the solutions is slowed down by the addition of HMDS. This should be due to the effects of TMS; the formation of three-dimensional network would be slowed down since trimethylsilyl group prohibits

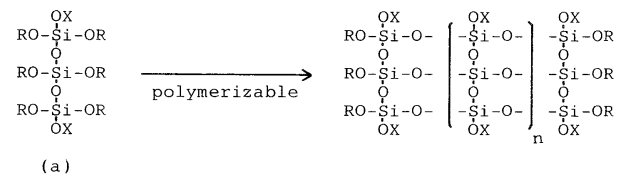

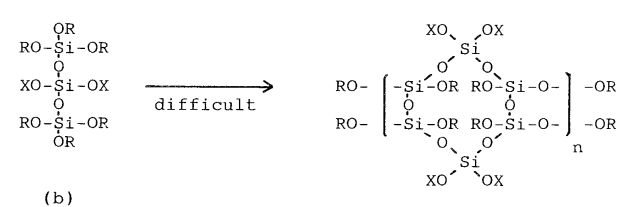

Fig. 3. A schematic representation of the difference of the formation of oligomers depending on the amount of added water. Oligomers of type (a) can polymerize to form linear polymeric particles while those of (b) have difficulties in the formation of linear polymeric particles.

further polymerization. It should be noted that MTES does not show an elongated duration for fiber drawing like the solutions of $r=0.5$ in spite of the fact that MTES has a methyl group impossible to polymerize.

The amount of water will be discussed. The decrease in MIW for $0<r<0.25$ is explained from a stoichiometric consideration since the number of the sites which undergo hydrolysis decreases with an increase in $r$. However, the following increase in MIW for $0.25<r<0.6$ and the increase in MAW for $0<r<0.6$ can not be explained from stoichiometry. For example, for $r=0.5$, spinnability occurs only when a stoichiometrically excess amount of water is added. $0.225 \mathrm{~mol}$ of water is stoichiometric for a complete hydrolysis of TEOS and HMDS. It is assumed that the amount of water may affect the type of TMS'ed units. For example, trimers TMS'ed on either terminal silicon atoms (Fig. 3. (a)) can polymerize to form linear polymeric particles with triple siloxane chains while those TMS'ed on the center silicons (Fig.3. (b)) would have difficulties in the formation of such linear polymeric particles. Addition of an excess amount of water may preferencially produce oligomers of the type of (a). Once these oligomers are produced, the excess amount of water would not play rolls. However, further studies are needed on this point.

\section{Conclusion}

(1) Preparation of silica glass fibers from tetraethylorthosilicate (TEOS) and hexamethyldisiloxane (HMDS) were studied. The duration for fiber drawing is elongated and spinnability is improved by an addition of HMDS. The range of added water for the occurrence of spinnability is 
widened with an increase in the ratio of silicon contained in HMDS to the total silicon, $r$.

(2) Spinnable solutions are obtained when the value of $r$ is less than 0.667 .

(3) It has been discussed that threedimensional polymerization would be slowed down by HMDS.

(4) It is assumed that the gel fibers obtained by this method would consist of linear polymeric particles with double or triple siloxane chains capped with trimethylsilyl groups.

(5) Gel fibers from the solutions of $r \leqq 0.5$ can be converted to silica glass fibers by the heat-treatment at $600^{\circ} \mathrm{C}$ or higher temperatures.

Acknowledgment The authors wish to thank Mr. Eizo Hiroki of Government Industrial Development Laboratory, Hokkaido for his experimental contribution.

\section{References}

1) S. Sakka, Am. Ceram. Soc. Bull., 64, 1463-66 (1985).

2) S. Sakka and K. Kamiya, J. Non-Cryst. Solids, 42, 403-22 (1980).

3) Idem., ibid., 48, 31-46 (1982)

4) K. Kamiya, S. Sakka and T. Mizutani, Yogyo-KyokaiShi, 86, 552-59 (1978).
5) K. Kamiya, T. Yoko and S. Sakka, ibid., 92, 242-47 (1984).

6) H. Ohta, "Proceedings of First International Symposium on New Glass", Ed. by The Association of New Glass Industries, Tokyo (1987) pp. 27-34.

7) K. Kamiya, M. Ohta and T. Yoko, J. Non-Cryst. Solids, 83, 208-22 (1986).

8) S. Sakka, Y. Tanaka and T. Kokubo, ibid., 82, 24-30 (1986).

9) H. Kozuka, H. Kuroki and S. Sakka, ibid., 100, 226-30 (1988).

10) S. Sakka, K. Kamiya and T. Kato, Yogyo-Kyokai-Shi, 90, 555-56 (1982).

11) C. J. Brinker and G. W. Scherer, J. Non-Cryst. Solids, 70, 301-22 (1985).

12) Y. Abe, N. Shintani and T. Misono, J. Polym. Sci. Polym. Chem. Ed., 22, 3759-69 (1984).

13) H. Yanaginuma, H. Ito and A. Tada, Preprints of 1988 Summer Meeting of Hokkaido Branch, The Chemical Society of Japan (1988) p. 20.

14) W. C. LaCourse, S. Dahar and M. M. Akhtar, J. Am. Ceram. Soc., 67, C 200-01 (1984).

15) M. Makihara and Y. Moriya, Yogyo-Kyokai-Shi, 92, 328-33 (1984).

16) Idem., Bull. Gov. Ind. Res. Inst., Osaka, 35, 1-6 (1984).

17) M.F. Bechtold, R. D. Vest and L. Palmbeck, J. Am. Chem. Soc., 90:17, 4590-98 (1968). 